\title{
EL CARÁCTER EXTRAPATRIMONIAL DE LA COMPENSACIÓN ECONÓMICA Y SU RENUNCIA
}

["The Non-Patrimonial Nature of Economic Compensation and its Waiving"]

\author{
RODRIgo BARCIA LEHMANN* \\ Universidad Finis Terrae, Santiago, Chile \\ Carolina Riveros Ferrada** \\ Universidad Central, Santiago, Chile
}

\section{RESUMEN}

La compensación económica es un derecho extrapatrimonial y postmatrimonial, que tiene una función principalmente resarcitoria, y, en algunos supuestos, complementaria o exclusivamente asistencial. Este trabajo aplica tal tesis a la renuncia de la compensación económica, y se aparta de soluciones rígidas; y critica las soluciones del Derecho civil tradicional, alejadas de un Derecho de familia fuertemente analítico y sustentado en claros principios propios, que lo diferencian de otras áreas del Derecho Privado.

\begin{abstract}
Financial compensation is an intangible and post-matrimonial right, function of which is mainly aimed at indemnifying the party in question and, based on some other assumptions, has a complementary function or a function to exclusively provide assistance. This work applies said thesis to the waiver of financial compensation and sets inflexible solutions apart; it also criticizes the traditional civil Law solutions, away from a strongly analytic family Law and based on its own inherent principles, which makes it different from other areas of the Private Law.
\end{abstract}

* MBA en Economía y Dirección Internacional de Empresas por la Universidad Autónoma de Madrid, 1997; European Master in Law and Economics por la Universidad Complutense y la Hamburg Universität, 1998; doctor en Derecho Privado por la Universidad Complutense de Madrid, 2002; profesor de la Facultad de Derecho de la Universidad Finis Terrae. Dirección electrónica: rbarcia@uft.cl

"Magíster en Derecho por la Ruprecht-Karls-Universität Heidelberg; doctora en Derecho por la Ludwig-Maximilian-Universität; profesora de Derecho Civil de la Universidad Central de Chile. Correo electrónico: criverosf@ucentral.cl Agradecemos la gentileza del profesor de Derecho Civil don Juan Francisco Sepúlveda por la información ofrecida acerca del Derecho italiano. 
Palabras Clave

Compensación económica - Derecho de familia - Divorcio.
KEYWORDS

Financial compensation - Family law - Divorce.

[RECibido el 17 de mayo y ACEPTADo el 15 de julio de 2011].

\section{INTRODUCCIÓN}

Este artículo está relacionado con otro trabajo en el cual sostenemos que la compensación económica es una institución extrapatrimonial, que fundamentalmente promueve acuerdos de distribución del trabajo en el seno de la familia ${ }^{1}$. Creemos que esta concepción de la compensación económica es acertada y nos lleva a entender la renuncia a la compensación económica, conforme a los principios que configuran el Derecho de familia y de la infancia.

En resumen, este artículo plantea los criterios que debe considerar el juez al momento de calificar la compensación económica como renunciable.

\section{Planteamiento}

El criterio fundamental para determinar la renunciabilidad a la compensación económica no es absoluto y depende de si se renuncia al derecho extrapatrimonial de la compensación económica, que es renunciable sólo en su vertiente resarcitoria o si se renuncia al derecho en cuanto a su función asistencial, la que, en principio, es irrenunciable. Señalamos que lo es sólo en principio, porque dicho derecho será renunciable en la medida que él se traduzca en un derecho asistencial concreto.

Nuestra propuesta, en torno a la renuncia de la compensación económica, deberá hacerse bajo dos respectos. El primero es el momento en que se realiza dicha renuncia: un pacto prematrimonial, durante la vigencia del matrimonio o en un estadio posterior, esto es, una vez iniciado el procedimiento de nulidad o divorcio. Y el segundo aspecto por analizar es el contenido de la renuncia. El marco regulatorio de este análisis de contenido es la renuncia de la compensación en sí misma y la apreciación de los diversos efectos jurídicos del divorcio, considerando especialmente los principios de la autonomía privada y la protección al cónyuge más débil, plasmado en el artículo 3 LMC. Para realizar este estudio pasamos a revisar algunas tendencias en el Derecho comparado.

\footnotetext{
${ }^{1}$ BARCiA, Rodrigo - Riveros, Carolina, El carácter extrapatrimonial de la compensación económica, en Revista Chilena de Derecho (en proceso de publicación).
} 


\section{ANÁlisis DEL DERECHO COMPARADO EN GENERAL Y ESPECIALMENTE DE LOS DERECHOS ALEMÁN Y ESPAÑOL}

En el Derecho comparado se aprecia una regulación distinta de las convenciones y pactos matrimoniales, según su fecha de la estipulación, es decir, si se celebran antes del matrimonio, al momento de su suscripción o con posterioridad-, y de acuerdo a la fuerza que se le dé al principio de la autonomía privada en la normativa relativa a la regulación de la ruptura. Así, en el Derecho del "Common law" podemos apreciar dos tendencias contrapuestas.

En los Estados Unidos de América los pactos prematrimoniales son totalmente válidos y la anticipación de las consecuencias de la ruptura es plenamente admitida. De este modo, se ha consignado en la Uniform Premarital Agreement Act de 1983 y los Principies of the Law of Family Dissolution de la American Law Institute del 2000. En cambio, en el Reino Unido, desde del caso "Hyman v. Hyman" (1929) se estima que sólo los tribunales pueden sentar las bases patrimoniales del divorcio y por ende, los tribunales fallan incluso en contra de un acuerdo o pacto de los cónyuges firmado con antelación a la ruptura del matrimonio ${ }^{2}$. En Italia los tribunales consideran que la pensión por divorcio es indisponible en atención a su naturaleza asistencial o por ilicitud de la causa; y lo establecido en el artículo 160 CCIt. ${ }^{3}$. En resumen, los tribunales en Italia prohíben esta clase de pactos ${ }^{4}$.

En el Derecho alemán no existe un sistema compensatorio posmatrimonial como en el Derecho chileno, francés o español; sin embargo en aquel ordenamiento jurídico se establecen alimentos post-matrimoniales. Nos detendremos en el sistema jurídico alemán, por cuanto creemos que el

${ }^{2}$ En este sentido, Probert, Rebecca, Cretney and Probert's Familly Law (Sweet \& Maxwell, Thomson Reuters, Seventh Edition, Great Britain, 2009), p. 164, señala que "[i] $t$ is clear that a pre-nuptial agreement is not enforceable in the usual contractual sense. The long-standing objection to the enforceability of such agreements is that they are contrary to public policy, as they envisage the ending of the marriage before it has even begun".

${ }^{3}$ Cim cita 71, Cass. 18/2/2000, No 1810, Corr. giur. (2000), p. 1021; Cass. 7 de septiembre de 1995, N 9416, Dir. fam. pers. (1996), p. 931; Cass. 28 de octubre de 1994, No 8912, Fam. dir. (1995), p. 14; Cass. 4 de junio de 1992, N 6857, Corr. giur. (1992), p. 863; Cass. 11 de diciembre de 1990, $\mathrm{N}^{\circ} 11.788$, Giur. it. (1992), I, 1, c. 156; Cass. 11 de junio de 1981, N³777, ivi, 1981, I, c. 1553 [disponibles en http://www. ceflonline.net; fecha de consulta: 14 de diciembre de 2010].

${ }^{4}$ De esta forma ha fallado la Corte de Casación italiana, en sentencias de 18 de febrero y 14 de junio, ambas del 2000, como destaca EGEA, Jean, Pensión compensatoria y pactos en previsión de una ruptura matrimonial, en Estudios juridicos en homenaje al profesor Luis Diez-Picazo (Madrid, 2002), III, pp. 4.555. 
entender cómo funciona un sistema asistencial -que complementariamente cumple la compensación económica en nuestro sistema- es clave, a su vez, para determinar cómo opera la renuncia. En comparación con otros sistemas jurídicos se puede indicar que el sistema alemán privilegia la autonomía privada; aunque, como veremos, lo hace con importantes limitaciones 5 . La regulación de los pactos de alimentos post-matrimoniales establecida en el $\$ 1585$ letra c) BGB. se modificó en el año $2008^{6}$. De acuerdo a dicha reforma, es menester, que los cónyuges, que deseen celebrar un acuerdo relativo a los alimentos, redacten un documento notarial, antes de dictada la sentencia de divorcio [ $\$ 1585$ letra c) BGB.], o que, en su caso, celebren un pacto protocolizado dentro del proceso de familia [ $\$ 127$ letra a) BGB.]. Los pactos que no cumplen con las mencionadas formalidades adolecen de nulidad ( $\$ 125 \mathrm{BGB}$.). Ahora bien, a diferencia de los pactos que se celebran con anterioridad a la sentencia de divorcio, todos los pactos posteriores al divorcio no requieren ninguna clase de formalidad.

El contenido de los pactos se rige por el principio de autonomía privada, es decir, todo lo referido a su cuantía, modalidad y pago del derecho de alimentos queda entregado a los cónyuges ${ }^{7}$. De este modo se puede pactar una modificación o una concretización de las normas legales relativas a los alimentos ${ }^{8}$. A estos pactos le son naturalmente aplicables, en subsidio, todas las normas materiales y procesales de los alimentos post-matrimoniales ${ }^{9}$.

La renuncia anticipada al derecho de alimentos post-matrimonial es permitida ${ }^{10}$. Sin embargo, desde los fallos del Bundesverfassungsgericht, de

${ }^{5}$ Martiny, Dieter, Ehescheidung und nachehelicher Unterhalt in Europa, en Electronic Journal of Comparative Law,(2004) [disponible en: http://www.ejcl.org/83/ art.83-hmtl].

${ }^{6} \mathrm{El}$ referido párrafo el BGB. establece lo siguiente: "Vereinbarung über den Unterhalt. Die Ehegatten können über die Unterhaltspflicht für die Zeit nach der Scheidung Vereinbarungen treffen. Eine Vereinbarung, die vor der Rechtskraft der Scheidung getroffen wird, bedarf der notariellen Beurkundung. $\$ 127$ a findet auch auf eine Vereinbarung Anwendung, die in einem Verfahren in Ehesachen vor dem Prozessgericht protokolliert wird".

${ }^{7}$ Borth, Helmut, en Schwab, Dieter (editor), Handbuch des Scheidungsrechts ( $4^{a}$ edición, München, Vahlen, 2000), IV, Rn. 1284 s.

${ }^{8}$ Oberlandesgericht Zweibrücken, en Zeitschrift für das gesamte FamilienrechtEhe und Familie im privaten und öffentlichen Recht (2007), p. 2.073.

${ }^{9}$ Gernhuber, Joachim - Coester-Waltjen, Dagmar, Lehrbuch des Familienrechts ( 5 a edición, München, C. H Beck, 2006), $\$ 30$ XII Rn. 161; JoHANnsEN, Kurt - Henrich, Dieter - BütTner, Helmut Eherecht (4a edición, München, C. H Beck, 2003), \$1585c Rn. 10.

${ }^{10}$ Oberlandesgericht Koblenz, en Zeitschrift für das gesamte Familienrecht- Ehe und Familie im privaten und öffentlichen Recht (2007), p. 479; Meder, Stephan, Der Unterhaltsverzicht im Spannungsfeld von Privatautonomie und Öffentlichem Interesse, 
$2001^{11}$ y del Bundesgerichtshof, de $2004^{12}$, se establecieron limitaciones a los pactos o contratos matrimoniales que se sustentan en la autonomía privada. Dichas limitaciones son también aplicables a los pactos de divorcio y por ello, a los pactos relativos a los alimentos post-matrimoniales ${ }^{13}$.

El arriba mencionado fallo del Bundesverfassungsgericht se refería a un pacto prematrimonial celebrado entre los novios, por el cual se acordó una separación de bienes como régimen patrimonial del matrimonio ${ }^{14}$, la exclusión de la compensación por pensiones previsionales y la recíproca renuncia a los alimentos post-matrimoniales. Es importante destacar que el pacto no se consideró una manifestación y resultado de una relación igualitaria, sino desequilibrada, por cuanto la mujer firmó el pacto estando embarazada y como una especie de compensación a favor del esposo, quién de esta manera aceptaba celebrar el matrimonio. El fallo del Bundesverfassungsgericht acogió la teoría del núcleo de los derechos fundamentales a los efectos jurídicos del divorcio, reconociendo una especie de graduación dentro de sus distintos efectos. Entre más directamente se afecte al núcleo de los derechos esenciales del matrimonio -o del divorcio, si se quiere-, más complejas y perjudiciales son las consecuencias para uno de los cónyuges y, por ende, el ámbito de la renunciabilidad de los derechos es menor ${ }^{15}$. De este modo, en el Derecho alemán, en el núcleo central de los efectos jurídicos del divorcio, se encuentran los alimentos, que se deben a los hijos ( $\$ 1570$ BGB.), en un segundo lugar están los alimentos, que se deben a los cónyuges en razón de una enfermedad ( $\$ 1572$ BGB.) o de su edad ( $\$ 1571$ BGB.) y la compensación

en Familie und Recht(Heft (1993) 1, p. 12. La voluntad de renunciar debe ser prestada clara y directamente. Sólo excepcionalmente es aceptada la renuncia tácita, es por ello, que por el sólo hecho de que el obligado no pague no se entiende que el titular del derecho está renunciando a éste. (Oberlandesgericht Stuttgart, Zeitschrift für das gesamte Familienrecht-Ehe und Familie im privaten und öffentlichen Recht (1999), p. 1136; Oberlandesgericht Schleswig, Zeitschrift für das gesamte Familienrecht-Ehe und Familie im privaten und öffentlichen Recht (1993), p. 72, JOHANNSEN, Kurt - HenRICH Dieter - BüttNer, Helmut, cit. (n. 9), $\$ 1585$ c Rn. 7; WeInreich, Gerd - Klein, Michael, Kompakt Kommentar Familienrecht (Luchterhand, Kriftel, 2002), §1585 c Rn. 50.

${ }^{11}$ Bundesverfassungsgericht, Zeitschrift für das gesamte Familienrecht-Ehe und Familie im privaten und öffentlichen Recht (2001), p. 343.

${ }^{12}$ Bundesgerichtshof, Zeitschrift für das gesamte Familienrecht-Ehe und Familie im privaten und öfentlichen Recht (2004), p. 601.

${ }^{13}$ Weinreich, Gerd - Klein, Michael, cit. (n. 10), $\$ 1585$ c Rn. 4; Oberlandesgericht Thüringen, en Zeitschrift für das gesamte Familienrecht- Ehe und Familie im privaten und öffentlichen Recht (2007), p. 2079.

${ }^{14}$ En este sentido debe considerarse que el régimen legal matrimonial supletorio en Alemania es el régimen de participación en los gananciales, $\$ \$ 1363$ ss. BGB.

${ }^{15}$ Borth, en SCHWAB, cit. (n. 7), IV Rn. 1332c. 
de pensiones o cotizaciones previsionales ( $\$ 1587$ ss. BGB.); y en un tercer lugar se encuentran los alimentos en razón de cesantía ( $\$ 1573$ BGB.). Los alimentos complementarios ( $\$ 1573$ inciso $2^{\circ} \mathrm{BGB}$.) y los alimentos debidos para el financiamiento de la educación o del perfeccionamiento profesional de uno de los cónyuges ( $\$ 1575$ BGB.), porque en el fondo se compensa a quien no pudo estudiar o seguir estudiando porque se casó ${ }^{16}$, se ubican en un lugar posterior, y el crédito de participación en los gananciales ( $\$ \$ 1363$ ss) es el derecho que está más alejado de este núcleo y por ende, es un derecho renunciable. De este modo, si se consideran todos los efectos jurídicos del divorcio, el crédito de participación en los gananciales es -en este contexto- lo más disponible, debido a su naturaleza marcadamente patrimonial. Ello a diferencia de nuestro Derecho, en que, por una parte, el crédito de participación en los gananciales -que de acuerdo al artículo 1792-20 CC.es sorprendentemente irrenunciable, y, por la otra, los gananciales de la sociedad conyugal que son renunciables en los momentos y de la forma que la ley establece.

En el Derecho alemán, los cónyuges pueden determinar de acuerdo a sus propias ideas, convicciones y necesidades su comunidad de vida y definir si están dispuestos o no a renunciar a algún o a todos los efectos jurídicos del divorcio ${ }^{17}$. Sin perjuicio de lo cual, es inadmisible que solo uno de los cónyuges asuma una carga injustificada en relación a los efectos del divorcio, como si solo él renuncia a los cónyuges a los alimentos post-matrimoniales. En torno a lo que nos interesa el Bundesgerichtshof, en el fallo antes indicado, estableció que el control de contenido de los pactos era una labor entregada a los tribunales ${ }^{18}$.

En síntesis, podemos indicar que los pactos matrimoniales y de divorcio se rigen por el principio de la autonomía privada; pero con limitaciones; y consecuentemente con ello la renuncia a los derechos, que emanan del divorcio, es admisible en la medida que no afecte el núcleo fundamental del derecho. En este sentido, también es preciso indicar que para la doctrina alemana el matrimonio y la familia son garantías constitucionales, que deben ser protegidas en

${ }^{16}$ Esta hipótesis de alimentos dice relación con la posibilidad de que el cónyuge que abandonó o no pudo estudiar o perfeccionarse en razón del matrimonio o la familia pueda con la ayuda financiera del otro cónyuge estudiar o perfeccionarse para luego poder generar sus propios ingresos.

${ }^{17}$ LANGENFELD, G., Handbuch der Eheverträge und Scheidungsvereinbarungen ( $4^{\mathrm{a}}$ edición, München, C.H Beck, 2000), Rn. 45, 80.

${ }^{18} \mathrm{El}$ control de contenido judicial se realiza en dos fases, en primer lugar se efectúa un primer control de acuerdo al $\$ 138$ inciso $1^{\circ}$ BGB. y un segundo control -sólo si el primer control fue aprobado- según el $\$ 242$ BGB. 
su carácter de institutos ${ }^{19}$. Esta es una tesis conocida para los constitucionalistas chilenos ${ }^{20}$, y lo interesante de ella es que es plenamente aplicable en Chile. De este modo, los tribunales de familia deben velar por el respeto de los derechos esenciales que rigen el estatuto jurídico del divorcio o la nulidad. Esta tesis es perfectamente aplicable en Chile y en virtud de ella no es posible renunciar a la compensación económica en la medida que ella cumpla un rol asistencial. En el sistema chileno el control de contenido de los jueces es ex-post y la renuncia en principio es válida, pero puede ser nula en la medida que afecte la función asistencial de la compensación económica aspecto que se debe revisar por el juez al momento de la nulidad o el divorcio.

El panorama en el Derecho español, antes de la Reforma del 2005, era un poco más confuso; pero muy interesante para nuestro análisis, desde que este ordenamiento jurídico fue uno de los antecedentes fundamentales de nuestra compensación económica. Antes de la Reforma, para algunos autores, la compensación económica era renunciable en cualquier momento ${ }^{21}$; en cambio para otros autores la renuncia sólo podría producirse una vez trabada la litis, tanto en la separación, como en el divorcio ${ }^{22}$.

${ }^{19}$ Entre otros: Di FabIo, Udo, Der Schutz von Ehe und Familie: Verfassungsentscheidung für die vitale Gesellschaft, en Neue Juristische Wochenachrift (2003), pp. 993; Pieroth Bodo - Schlink, Bernard, Grundrechte Staatsrecht (18 a edición, Heidelberg, C. F. Müller, 2002), II, p. 663.

${ }^{20}$ En este sentido, en la doctrina chilena, véase a Aldunate Eduardo - Fuentes, Jessica, El concepto de derecho de propiedad en la jurisprudencia constitucional chilena y la teoría de las garantías de instituto, en Revista de Derecho de la Universidad Católica de Valparaíso, 18 (1997): Actas de las XXVII Jornadas de Derecho Público, pp. 195-221.

${ }^{21}$ Son varios los autores que se inclinan por la renuncia a la compensación económica, como De La Cámara Álvarez, García Rubio, Montero Aroca, Pastor Vita, Roca Trías, Zarraluqui Sánchez-Eznarriaga, entre otros. En este sentido resuelve la sentencia de la Audiencia Provincial de Barcelona que dispone que "[...] la doctrina ha puesto de relieve que el derecho de pensión [...] es renunciable, sin que a ello sea obstáculo la ausencia de mención a la renuncia del artículo 101 del Código Civil [...]”. Véase: SAURA, Beatriz, La pensión compensatoria; criterios delimitadores de su importe y extensión (Valencia, Tirant lo Blanch, 2004), p. 73.

${ }^{22}$ Marín, Teresa, Acuerdos de los cónyuges en la pensión por separación y divorcio (Valencia, Tirant lo Blanch, 1995), p. 69; GARcía, María Paz, Los pactos prematrimoniales de renuncia a la pensión compensatoria en el Código Civil, en Anuario de Derecho Civil,, 56 (2003) 4, p. 1654. Una opinión distinta expresa Barral, Inmaculada, La separación de bienes, en MALuQuer De Motes, Carlos (coordinador), Derecho de familia. Análisis desde el Derecho catalán (Barcelona, Bosch, 2000), p. 151, quien señala: "[s] e ha afirmado que el derecho a la compensación económica es renunciable antes de la extinción del régimen, por ejemplo como un pacto contenido en capitulaciones matrimoniales en previsión de la ruptura del matrimonio que permite el art. 15 CF.; pero a mi entender, y a pesar del principio de libertad civil que informa esta materia, pensando en la relación estrecha que este precepto tiene con la protección del cónyuge económi- 
Sin perjuicio de estas discusiones doctrinales, los tribunales de justicia de forma mayoritaria consideraron que el derecho a percibir la pensión compensatoria es un derecho dispositivo, y, por regirse enteramente por el principio de la autonomía de la voluntad, renunciable ${ }^{23}$.

Un cónyuge, como destaca García, podría renunciar a la compensación económica de forma gratuita u onerosa. En los supuestos de renuncia onerosa un cónyuge podría, a cambio de la renuncia, transferir un derecho real sobre inmueble. Por tanto se podría solicitar, al CBR., la inscripción de la respectiva escritura pública -como por ejemplo de una capitulación matrimonial-por la que transfiere la propiedad de un bien raíz a favor del cónyuge renunciante por parte del cónyuge beneficiado con la renuncia ${ }^{24}$. En el Derecho español, se acepta la inscripción de estos pactos en la Dirección General de los Registros de España, aún sin aprobación judicial. Ese organismo resolvió que estos pactos se sustentan en la autonomía privada y por tanto son válidos ${ }^{25}$. Independientemente de ello, detengámonos en los argumentos que se daban para desechar la renuncia, antes de la Reforma del 2005:

a) La renuncia atentaba contra el principio de igualdad entre los cónyuges. Este argumento, que también se puede sostener en el Derecho chileno, debe desecharse por cuanto la igualdad no tiene porqué verse afectada por la renuncia desde que el ordenamiento jurídico establece una serie de mecanismos a través de los cuales se resguarda dicho principio, como la existencia de un régimen supletorio de comunidades de bienes, la declaración de bien familiar, etc. ${ }^{26}$.

camente más débil, la compensación es irrenunciable antes de su nacimiento; pero una vez sobrevenida la situación de crisis, el cónyuge que la tiene a su favor podrá dejar de solicitarla”. La referencia al CF. es al ex Código de Familia catalán, cit (n. 32).

${ }^{23}$ Sentencia de la Audiencia Provincial de Zaragoza, de 15 de noviembre de 2002, AC (2002(, 1863; y Sentencia de la Audiencia Provincial de Granada, de 9 de abril de 2007, JUR (2007), 271736.

${ }^{24}$ García, María Paz, cit. (n. 22), p. 1.666.

${ }^{25}$ GARCía, María Paz, La pensión compensatoria tras la separación o el divorcio en el derecho español, en Cuadernos de análisis jurídicos, Colección Derecho Privado, V: Compensación económica por divorcio o nulidad (Santiago, Ediciones Universidad Diego Portales, Escuela de Derecho, 2009), pp. 96-102.

${ }^{26}$ PASTOR, Francisco, La renuncia anticipada a la pensión compensatoria en capitulaciones matrimoniales, en Revista de Derecho de familia, 19 (Valladolid, 2003), pp. 52-53; García, María Paz, cit. (n. 22), pp. 1668-1673 Una interesante sentencia de la Corte Suprema desecha la aplicación mecánica del artículo 145 inciso $3^{\circ}$ CC., que dispone que "[i]gual regla [se refiere a la desafectación del bien como familiar] se aplicará si el matrimonio se ha declarado nulo o ha terminado por muerte de alguno de los cónyuges o por divorcio. En tal caso, el propietario del bien familiar o cualquiera de sus causahabientes deberá formular al juez la petición correspondiente". La Corte Suprema resolvió que la declaración de un bien como familiar puede subsistir al divorcio de los cónyuges en 
ciertos supuestos. En este sentido, la Cuarta Sala de la Corte Suprema, mediante un fallo de 15 de abril de 2009, en autos rol No 1086-2009, "Pacal con De la Fuente", resolvió, en sus considerandos, lo siguiente: "Sexto: Que tal conclusión se desprende del texto del artículo 145 del Código Civil, el cual para el caso en que el matrimonio sea declarado nulo o haya terminado por muerte de uno de los cónyuges o por divorcio, dispone que se aplicará la misma regla dada en el inciso anterior, disposición que se refiere a la posibilidad de desafectar un bien raiz que ya no sirva de residencia oficial de la familia, por la remisión que se hace, en definitiva, a lo dispuesto por el artículo 141 del citado Código. Dicho reenvio debe entenderse no sólo al procedimiento que debe utilizarse, esto es, a la necesidad de que exista una petición de desafectación y una resolución que la disponga, sino también la de justificar que ya no se cumplen con los fundamentos que autorizan la existencia de los bienes familiares, pues el inciso final del aludido articulo 145 del Código Civil, establece la exigencia de formular al juez la petición en este sentido, apareciendo entonces que la remisión que se hace bajo la expresión 'igual regla', seria una redundancia de la norma, si se interpreta en el sentido que se refiere sólo al procedimiento; por el contrario, aparece más razonable con la idea anterior, que se requiera de un pronunciamiento judicial en orden a acreditar el cumplimiento de los presupuestos de fondo referidos al destino del bien. Lo anterior se ve reafirmado, además, por la circunstancia que el divorcio no opera de pleno derecho desafectando el bien, pues se requiere de una decisión del órgano jurisdiccional en tal sentido, la que deberá valorar la situación particular. Séptimo: Que tal interpretación guarda, por lo demás, debida armonía con el sentido y finalidad que la institución de los bienes familiares representa, en el contexto que si bien ella está prevista para los casos en que existe matrimonio entre los involucrados, lo cierto es que con ella se intenta asegurar a la familia mediante la subsistencia en su poder de bienes indispensables para su desarrollo $y$ existencia, con prescindencia del derecho de dominio que sobre los mismos tenga uno de los cónyuges. En efecto, este instituto pretende asegurar a la familia un hogar fisico estable donde sus integrantes puedan desarrollar la vida con normalidad, ejerciendo los roles y funciones que les correspondan, aún después de disuelto el matrimonio, a fin de evitar el desarraigo de la que ha sido la residencia principal de ésta. Desde otra perspectiva constituye también una garantía oforma de protección para el cónyuge más débil o para el que tenga el cuidado de los hijos, en casos de separación de hecho o de disolución del matrimonio. Octavo: Que, en efecto, el objeto de los bienes familiares se centra en dar protección a la familia en la disposición de bienes materiales para su propio desarrollo, en cualesquiera de los regimenes patrimoniales que están consagrados en la ley; amparar al cónyuge no propietario de la vivienda familiar y resguardar el interés de los hijos comunes y del cónyuge al que le corresponde el cuidado de éstos, en los casos de rupturas conyugales, como separación de hecho, divorcio y nulidad". La Cuarta Sala de la Corte Suprema que emitió este fallo estuvo integrada por los ministros señor Patricio Valdés A., señora Gabriela Pérez P., señor Haroldo Brito C., y los abogados integrantes señores Roberto Jacob Ch. y Ricardo Peralta V.; su redacción correspondió al Ministro señor Patricio Valdés Aldunate. En cuanto al régimen de sociedad conyugal, este régimen no es beneficioso para la mujer, sobre todo respecto a la administración de sus bienes propios que ejerce el marido antes del matrimonio y los que adquiera durante el matrimonio a título oneroso y no ingresen en el patrimonio reservado; pero es un régimen sumamente conveniente para ella y desigual para el marido en torno a los bienes inmuebles, que se adquieren a título oneroso durante el matrimonio por los cónyuges. De este modo, los bienes raíces que adquiere la mujer a título oneroso, conforme al artículo 150 CC., ingresan a su 
b) La renuncia constituye un abuso de una parte dominante, sobre el denominado cónyuge débil. En el Derecho patrimonial estos abusos se corrigen a través de dos mecanismos. El clásico de los vicios de la voluntad, como el error, fuerza o dolo, y el más moderno que consiste en las denominadas cláusulas abusivas. Sin perjuicio de ello, esta intervención del Estado en los contratos tiene como sustento una falla de mercado, por ello económicamente esta intervención sólo se justifica en los casos de asimetría de información, costes de transacción o externalidades negativas. Sin embargo, estos argumentos, en principio, no son trasladables al Derecho de familia, desde que los contratos son una forma de concretizar expectativas económicas de las partes, como forma de aumentar la riqueza, y el Derecho de familia se sustenta en consideraciones fundamentalmente éticas y de expectativas a largo plazo.

c) La renuncia a la compensación económica afecta a una expectativa, y sólo puede renunciarse a un derecho ya constituido. Este argumento es especialmente relevante por cuanto, como los anteriores, se puede aplicar al Derecho chileno. Este tema fue abordado, por los tribunales españoles por un fallo de la Audiencia Provincial de Asturias, de fecha 12 de diciembre del $2000^{27}$. En virtud de esta sentencia se desechó la renuncia a la compensación económica por cuanto ella exigiría la afectación de un derecho con concreción patrimonial. En este sentido, la renuncia sólo opera respecto de un derecho subjetivo, que haya ingresado al patrimonio del renunciante. Sin embargo, la mayoría de la doctrina española desechó este argumento por diversas razones. De este modo, Pastor entiende que la renuncia a la compensación puede ser entendida como una renuncia a la ley, de acuerdo al artículo $6.2^{\circ}$ CCEsp. en cuyo texto se acepta expresamente "la exclusión voluntaria a la ley aplicable"28. Egea agrega que, en virtud del principio de la autonomía privada, se puede renunciar a una expectativa, y ello se acepta en varios campos del Derecho, como si se renuncia a exigir el nivel de cuidado que establece la ley

patrimonio reservado, y son administrados solamente por la mujer. Incluso pudiendo disponer de ellos, sin requerir autorización del marido. A su vez, los bienes raíces que adquiere el marido, durante la sociedad conyugal a título oneroso, también ingresan a la sociedad conyugal; pero de una forma totalmente diferente, ya que, la administración del marido está sustancialmente limitada, requiriendo la autorización de la mujer para una serie de actos, incluidos los de disposición. Por otra parte, si a la mujer profesional no le conviene el régimen de sociedad conyugal, siempre podrá renunciar a los gananciales y quedarse con el patrimonio reservado. De este modo, la mujer no siempre se rige por las reglas de la comunidad de bienes.

${ }^{27}$ EgEA, Jean, cit. (n. 4), p. 4.568.

${ }^{28}$ Pastor, Francisco, cit. (n. 26), p. 39. En este sentido se puede consultar: EgEA, Jean, cit. (n. 4), p. 4.555; García, María Paz, cit. (n. 22), p. 1.658; y Pastor, Francisco, cit. (n. 26), p. 44. 
al deudor, en el cumplimiento de las obligaciones ${ }^{29}$ o como sucede, entre nosotros, respecto de la renuncia a los gananciales.

En el Derecho español, la Ley $N^{\circ}$ 15/2005 vino a zanjar definitivamente esta discusión, en la nueva redacción que le dio al artículo 97 CCEsp., otorgándole a la pensión económica un carácter netamente resarcitorio, que vino a determinar su renunciabilidad ${ }^{30}$. Sin perjuicio de lo cual, algunos autores estiman que los pactos prenupciales pueden ser declarados nulos en la medida que uno de los contrayentes posea un mayor poder negociador que el otro; que se afecten los derechos fundamentales de los cónyuges o los hijos o que se afecte a tercero; concurriendo circunstancias posteriores de una entidad suficiente, que conduzcan a la nulidad del pacto de renuncia de la pensión compensatoria ${ }^{31}$.

Recientemente en Cataluña se ha aprobado el libro II de su Código Civil, que trata sobre la persona y la familia, y que regula los pactos de previsión de una ruptura matrimonial en su artículo 231-20 ${ }^{\circ 32}$. Dicha norma reconoce, por un lado, la autonomía privada como un principio general del Derecho de familia y, a su vez, resguarda la eventual desigual posición de los cónyuges, protegiendo al cónyuge más débil de la relación, a través de una serie de

${ }^{29}$ EGEA, J, cit. (n. 4), p. 4.569, también indica ejemplos correspondientes al Derecho catalán.

${ }^{30}$ Pastor, Francisco, Estudios doctrinales, en Revista de Derecho de familia, 28 (Valladolid, 2005), p. 47.

${ }^{31}$ García, María Paz, cit. (n. 25), pp. 96-97.

32 "Artículo 231-20": "Pactos en previsión de una ruptura matrimonial. 1. Los pactos en previsión de una ruptura matrimonial pueden otorgarse en capitulos matrimoniales o en escritura pública. En el supuesto de que sean antenupciales, solo son válidos si se otorgan antes de los treinta dias anteriores a la fecha de celebración del matrimonio. 2. El notario, antes de autorizar la escritura a que se refiere el apartado 1, debe informar por separado a cada uno de los otorgantes sobre el alcance de los cambios que pretenden introducirse con los pactos respecto al régimen legal supletorio y debe advertirlos de su deber recíproco de proporcionarse la información a que se refiere el apartado 4. 3. Los pactos de exclusión o limitación de derechos deben tener carácter recíproco y precisar con claridad los derechos que limitan o a los que se renuncia. 4. El cónyuge que pretenda hacer valer un pacto en previsión de una ruptura matrimonial tiene la carga de acreditar que la otra parte disponia, en el momento de firmarlo, de información suficiente sobre su patrimonio, sus ingresos y sus expectativas económicas, siempre y cuando esta información fuese relevante con relación al contenido del pacto. 5. Los pactos en previsión de ruptura que en el momento en que se pretende el cumplimiento sean gravemente perjudiciales para un cónyuge no son eficaces si este acredita que han sobrevenido circunstancias relevantes que no se previeron ni podian razonablemente preverse en el momento en que se otorgaron". En Cataluña, la Ley $N^{\circ}$ 25/2010, de 29 de julio -que aprobó el libro II del Código Civil, relativo a la persona y la familia-derogó el Código de Familia. 
mecanismos formales y de contenido, tanto respecto de la celebración del convenio, como con posterioridad.

\section{LA RENUNCIA DE LA COMPENSACIÓN ECONÓMICA EN EL DERECHO CHILENO}

Una objeción al planteamiento sostenido en este trabajo podría ser que al entenderse que la regla general es que los derechos extrapatrimoniales son irrenunciables, la compensación económica por ser un derecho extrapatrimonial -como hemos sostenido-, también es irrenunciable. Este argumento no nos parece definitivo. Ello se debe a que, muchos derechos a pesar de ser extrapatrimoniales son perfectamente renunciables. Así sucede, por ejemplo, con el ejercicio de la patria potestad, que siendo un derecho extrapatrimonial $^{33}$, es renunciable ${ }^{34}$. Pero, la razón fundamental por la cual las reglas generales, en el Derecho de familia, pueden revisarse, es que esta rama del Derecho privado está fuertemente relacionada con los derechos fundamentales y que opera como un sistema jurídico que se sustenta en principios. De esta forma, es un Derecho que crea una clara estructura de principios, máximas y normas que son aplicables por el juez de forma concreta. No por nada el principio fundamental del Derecho de la infancia es el del interés superior del niño o adolescente y el del Derecho de familia es de la protección de la familia y la intervención mínima del Estado. Por ello, reconocemos, en el Derecho de familia, un sistema dúctil y coherente con los principios que lo inspiran.

A continuación nos referiremos al estatuto jurídico que regula la renuncia de los derechos extrapatrimoniales en el Derecho chileno, reconociendo básicamente que la renuncia no está regulada, a lo menos de forma expresa.

\section{La renuncia a los gananciales en los regimenes de sociedad conyugal y} participación en los gananciales.

Creemos necesario, antes de referirnos a renuncia a la compensación económica, analizar someramente los regímenes patrimoniales del ma-

${ }^{33}$ Ello también es reconocido por Larenz, Karl - Wolf, Manfred, Allgemeiner Teil des Bürgerlichen Rechts (9a edición, 2004), $\$ 15$, p. 256. Estos autores se refieren a la patria potestad como un ejemplo de Derecho de familia que no poseen ningún carácter patrimonial.

${ }^{34} \mathrm{La}$ diferencia entre las nociones de titularidad y ejercicio de la patria potestad se encuentran aclaradas, en el Derecho argentino, por Bossert Gustavo - ZANNONI, Eduardo, Manual de Derecho de familia ( $5^{\text {a }}$ edición actualizada, Buenos Aires, Astrea, 2004), pp. 556-557. En el Derecho español es una distinción de tal importancia que cualquier obra general en Derecho de familia la contiene. 
trimonio en Chile. Así, podemos observar que en el régimen de sociedad conyugal, la mujer puede renunciar a los gananciales ${ }^{35}$; en cambio en el régimen de participación en los gananciales se prohíbe no sólo la renuncia, sino que cualquier convención o contrato respecto al eventual crédito de los gananciales ${ }^{36}$. En opinión de Corral, el crédito de participación en los gananciales se refiere a un crédito que envuelve dos finalidades, por un lado intenta corregir la desigualdad, en cuanto a la diferencia en la acumulación de bienes materiales por los cónyuges y, por la otra, es un reflejo del consorcio de vida y de intereses patrimoniales, que, durante la vigencia del régimen, se ven postergados en pos de la independencia patrimonial de los esposos o cónyuges según el caso ${ }^{37}$. Además, el mismo autor agrega que esta figura posee un claro elemento de justicia, mas tiene como instrumento un crédito propiamente tal, que se disciplina por el Derecho de las obligaciones ${ }^{38}$. A pesar de la posición de Corral, que compartimos, la contradicción existente en la regulación de la renuncia en ambos regímenes económicos del matrimonio no sólo es evidente, sino difícil de justificar. Y ello se acrecienta si en ambos regímenes patrimoniales del matrimonio se reconocen marcadamente aspectos comunes de índole patrimonial. No encontramos sustento a la diferenciación por la cual a la mujer se le permita, bajo el régimen de sociedad conyugal, renunciar a los gananciales y, en el caso de la participación en los gananciales, se le niegue tal posibilidad a ambos contrayentes. En este sentido, verificamos que, en nuestro Derecho de familia, por lo menos en torno a la renuncia de los gananciales, en los regímenes de sociedad conyugal y participación en los gananciales, no existe coherencia. El argumento acerca de que el crédito de participación es solamente eventual ${ }^{39} \mathrm{y}$, como consecuencia de ello, es improcedente celebrar cualquier pacto a este respecto, nos parece inconsistente, en cuanto tampoco existen los gananciales al momento de celebrar una capitulación matrimonial.

La inconsistencia en la solución adoptada por nuestro Derecho se puede considerar como una consecuencia del ámbito temporal de las regulaciones. La renuncia a los gananciales, en la sociedad conyugal, obedece a la lógica

${ }^{35}$ Artículo 1719 CC.

${ }^{36}$ Artículo 1792-20 CC.

${ }^{37}$ Corral, Hernán, El crédito de participación en los gananciales en el sistema económico matrimonial chileno, en CORRAL, Hernán (editor), Los regimenes matrimoniales en Chile (Santiago, Universidad de los Andes, 1998), p. 159.

${ }^{38}$ Corral, Hernán, cit. (n. 37), p. 160.

${ }^{39}$ Para Rodríguez, Pablo, Regímenes matrimoniales (Santiago, Editorial Jurídica de Chile, 1996), p. 240, este derecho eventual debe entenderse como un derecho sujeto a condición suspensiva; para CORRAL, Hernán, cit. (n. 37), pp. 161-162, técnicamente no se trata de un derecho sujeto a condición suspensiva. 
imperante a la promulgación del Código Civil. Así, este derecho se sustentaba en el poder marital sobre la mujer, por lo que dentro de esta lógica, es perfectamente entendible la renuncia a los gananciales y las consecuencias que ella genera -como sucede con la pérdida de los frutos de los bienes propios de la mujer establecida en el artículo 1753 CC.-. A su vez, su mantención, una vez consagrado el patrimonio reservado de la mujer casada por el Decreto-ley $\mathrm{N}^{\circ} 328$ de 1925 y la Ley No 5.521 de 1934, obedece a que la renuncia a los gananciales le permite a la mujer quedarse con su patrimonio reservado, es decir, la renuncia puede ir en su beneficio. Por ello, es que la renuncia a los gananciales se permitiría en la sociedad conyugal, su objetivo es proteger a la mujer. En este sentido, si se permitiera la renuncia en la participación en los gananciales, ella debería ser recíproca y jamás perjudicar al denominado cónyuge débil. Esta era la forma de concebir el Derecho de familia que imperó en Chile hasta los ochenta. En cambio, la irrenunciabilidad del derecho para ambos conyuges más bien una concepción posterior que se basa en el deseo de impedir la discriminación a la mujer.

\section{Lapertinencia de la renuncia a la compensación económica, como derecho ex-} trapatrimonial, en la medida que no cumpla una función netamente asistencial.

Ahora bien, centrándonos en el tema de la compensación económica, no existe ninguna norma legal que permita o prohíba expresamente su renuncia. Pero, la nulidad no sólo puede ser expresa, sino que también puede ser tácita por lo que debemos analizar si la renuncia atenta contra algún principio fundamental del Derecho de familia. A su vez, el análisis de a los momentos en que los que eventualmente se puede producir la renuncia a la compensación económica nos lleva a abordar la validez de la renuncia en los pactos prematrimoniales, los que se generen durante el matrimonio o a su término. A este respecto, gran parte de la doctrina chilena, acepta la validez de la renuncia sólo una vez que se ha iniciado el juicio de nulidad o divorcio, es decir, se inclina la validez de una suerte de renuncia ex post ${ }^{40}$. Incluso se ha entendido, por algunos autores que, por ser un derecho de carácter patrimonial, es absolutamente renunciable en cualquier momento ${ }^{41}$. Así, una parte importante de nuestra doctrina se inclina por la validez de la renuncia prematrimonial o durante la vigencia de un matrimonio, es decir, acepta una renuncia anticipada de la compensación económica, aplicando los

${ }^{40}$ LEPIN, Cristián, La compensación económica. Efecto patrimonial de la terminación del matrimonio (Santiago, Editorial Jurídica de Chile, 2010), pp. 162-163.

${ }^{41}$ Pizarro, Carlos - VIdAL, Álvaro, La compensación económica por divorcio o nulidad matrimonial (Santiago, Legal Publishing, Abeledo Perrot, 2009), p. 125. 
artículos 1717 y 12 CC. ${ }^{42}$. Otros autores deniegan la posibilidad de una renuncia ex ante de la compensación ${ }^{43}$.

Como apreciará el lector, no nos adherimos a ninguna de las posiciones precedentes por cuanto, creemos que se debe distinguir varias situaciones, aplicando la protección del cónyuge débil a un derecho que concebimos como extrapatrimonial. Así, nos inclinamos por el camino más difícil, que es el determinar en qué casos se permite y en qué casos se prohíbe la renuncia.

Las posiciones que aceptan la renuncia a la compensación económica sin límites son una consecuencia de entenderla como un derecho patrimonial; es verdad que algunos autores matizan esta opinión, señalando que es un derecho patrimonial de familia ${ }^{44}$; pero como hemos sostenido no creemos que se pueda otorgarle ese carácter a la compensación económica. A este respecto creemos que debe distinguirse la compensación económica como derecho de familia, en cuyo caso es un derecho extrapatrimonial y las consecuencias de dicha declaración, que se traducen, generalmente, en un derecho patrimonial. Esta misma distinción se puede hacer respecto de los alimentos. Así, independientemente que estos derechos puedan dar lugar a un derecho personal o real, como si se establece un usufructo a favor de uno

${ }^{42}$ Pizarro, Carlos - Vidal, Álvaro, cit. (n. 41), p. 127, se adscriben a esta posición en consideración a que el artículo $12 \mathrm{del}$ CC es de aplicación general y permite la renuncia de cualquier derecho; y el artículo $1717 \mathrm{CC}$. exige que las capitulaciones no sean contrarias a las buenas costumbres ni a la ley. Sin perjuicio de lo anterior, VIDAL, Álvaro, La compensación económica por ruptura matrimonial. Una visión panorámica, en Cuadernos de Análisis Jurídicos, Colección Derecho Privado, V: Compensación Económica por Divorcio o Nulidad (Santiago, Ediciones Universidad Diego Portales, Escuela de Derecho, 2009), p. 68, había manifestado en un trabajo anterior la imposibilidad de la renuncia anticipada a la compensación económica. El referido autor se remite a los artículos 1717 CC. y 63 LMC. que dificultarían la renuncia anticipada, como también a la naturaleza familiar del derecho a la compensación y a que ella se sustenta en la protección del cónyuge más débil. También Gómez de LA Torre, Maricruz, Compensación económica en la nueva Ley de matrimonio civil, (Santiago, Colegio de Abogados de Santiago de Chile, 2005), p. 8, se inclina por la renunciabilidad de la compensación económica, manifestando que "la ley no se pronuncia respecto de la renuncia de la compensación, pero podría hacerse por aplicación del artículo 12 [...] es una situación similar a la renuncia de los gananciales en la sociedad conyugal”.

${ }^{43}$ Lepin, Cristián, cit. (n. 40), p. 158; CoRral, Hernán, La compensación económica en el divorcio y la nulidad matrimonial, en Revista Chilena de Derecho, 34 (2007) 1, p. 36 .

${ }^{44}$ BARrientos, Javier, La compensación económica como 'derecho' de uno de los cónyuges y obligación' correlativa del otro. De sus caracteres, en Revista Chilena de Derecho Privado, 9 (2007), pp. 40-42; Novales, Aránzazu, Compensación económica como derecho de familia ¿Cuál es el objeto de la compensación? en Revista Chilena de Derecho de familia, 1 (Centro de Investigaciones Jurídicas, Facultad de Ciencias Jurídicas y Sociales de la Universidad Central de Chile, 2009), pp. 41-42. 
de los cónyuges, su sustento está en las facultades y deberes personales del matrimonio. Estimamos que la compensación económica es un derecho extrapatrimonial que protege a quién durante el matrimonio, en favor del hogar común y/ o sus hijos, asumió determinadas desventajas, tanto en el plano personal como profesional. La responsabilidad compartida -por la manera en que se distribuyen las tareas y obligaciones en la familia- y la protección del cónyuge más débil justifican, en el ordenamiento jurídico chileno, la institución de la compensación económica. Y ello es más que evidente al observar las consideraciones asistenciales que contempla el artículo 62 inciso $1^{\circ}$ LMC. Ellas son una manifestación de una suerte de acuerdo en ocasiones explícito -o en la mayoría de los casos- implícito entre los cónyuges. Las normas que regulan la compensación económica son de orden público, pero sólo en el sentido que protegen al cónyuge débil en cuanto tal. De este modo, la debilidad de un cónyuge debe ser revisada por el juez en concreto, es decir, determinando si se da uno de los supuestos que nos lleven a calificar al renunciante como cónyuge más débil. Pero estos criterios sólo en la medida que sean asistenciales son irrenunciables. Ello es evidente, ya que, a un beneficio económico - que cumple la compensación económica cuando es meramente resarcitoria- se puede renunciar libremente, como son la mayoría de los criterios que determinan su procedencia y su cuantía, estos últimos establecidos en el artículo 62 inciso $1^{\circ}$ LMC.; mas no se puede renunciar a los criterios asistenciales por cuanto ellos son los que protegen al denominado cónyuge más débil ${ }^{45}$. Así, nuestro sistema jurídico compatibiliza adecuadamente la autonomía privada con la protección del cónyuge débil. De esta distinción se puede desprender que no se debe confundir la renuncia al derecho con la condonación de la deuda una vez dictada la sentencia ${ }^{46}$, como, por lo demás, ocurre respecto de los alimentos.

Por las razones precedentes estimamos -a diferencia de una parte importante de la doctrina chilena que acepta la renunciabilidad de la compensación económica y que sólo ve como límites los establecidos por las reglas generales en materia de contratación, tales como, el principio de la buena fe contractual $^{47}$ - que la renunciabilidad a la compensación económica está determinada por los principios y directrices del Derecho de familia y, en especial,

${ }^{45}$ Para algunos autores las normas de orden público configuran el derecho en su fase indisponible; pero una vez que este derecho se configura, es decir, al fijarse la litis en el divorcio o la nulidad se puede renunciar al derecho. En contra de esta opinión se manifiesta CoRral, Hernán, cit. (n. 43), p. 36, cuando señala que cualquier renuncia anticipada es inválida.

${ }^{46}$ Pizarro, Carlos, La compensación económica en la nueva ley de matrimonio civil, en Revista Chilena de Derecho Privado, 3 (2004), p. 102.

${ }^{47}$ Pizarro, Carlos - Vidal, Álvaro, cit. (n. 41), p. 127. 
por el principio de protección al cónyuge débil. Por ende, los pactos en que se renuncie a la compensación económica deben ser objeto de un control de contenido ex-post al acuerdo, desde la perspectiva mencionada.

Por otra parte, la aplicación del principio de protección del cónyuge débil sólo procede en la medida que la compensación económica sea exclusivamente asistencial o en la parte que lo es, como si concurren criterios resarcitorios conjuntamente con criterios asistenciales. En dicho análisis el juez debe efectuar un análisis global de los distintos efectos jurídicos del divorcio y de la nulidad. Así, es distinto renunciar a la compensación económica y suscribir un régimen de separación total de bienes, que realizar esta misma renuncia pactando un régimen de participación en los gananciales, en la cual el cónyuge renunciante salga ganancioso. El juez no puede dejar de analizar la situación patrimonial final de los cónyuges.

Unas preguntas que nos quedan por tratar de responder son: ¿en qué momento? y ¿qué juez debe realizar el control de legalidad de contenido de la renuncia? Creemos que la determinación de la calidad de cónyuge débil, por efectuarse en concreto, hacerse en cualquier momento inmediatamente anterior a la sentencia que ponga término al matrimonio por nulidad o divorcio y por ende, debe ser el Juez de Familia el llamado a hacer dicho control. De este modo por aplicación analógica del artículo 63 LMC. nos parece que el juez competente para aprobar la renuncia es el que conoce de la acción de divorcio o nulidad del matrimonio ${ }^{48}$. De este modo, independientemente del pacto que se celebre al respecto, está claro que dicho acuerdo, aún si es pre-matrimonial, debe someterse a la aprobación judicial. Ello, además, es consistente con el deber que tiene el juez de informar en la audiencia preparatoria de la existencia de la compensación económica (artículo 64 inciso $2^{\circ} \mathrm{LMC}$. $)^{49} \mathrm{y}$, con la aprobación del monto de la compensación que

${ }^{48} \mathrm{El}$ artículo 63 LMC., dispone: "[1] a compensación económica y su monto y forma depago, en su caso, serán convenidos por los cónyuges, si fueren mayores de edad, mediante acuerdo que constará en escritura pública o acta de avenimiento, las cuales se someterán a la aprobación del tribunal [se refiere a los juzgados de familia]".

${ }^{49}$ Una sentencia de la Corte de Apelaciones de Concepción ("Ulloa con Jaure Santibáñez", 2010) se refiere en especial a la obligación del juez de garantizar un momento procesal para solicitar o no la compensación económica. En ella se acoge un recurso de casación en la forma, en virtud de los siguientes considerandos: "6. Que, sobre el particular el profesor Pablo Rodríguez Grez, en artículo publicado en la Revista de la Universidad del Desarrollo Actualidad Jurídica N²0, julio 2009, Tomo I, página 365 y siguientes, denominado "Ley de Matrimonio Civil: interpretación, efectos e insuficiencia”, señala que 'La compensación económica del artículo 61 de la LMC es un derecho sujeto a caducidad (extinción por el solo ministerio de la ley al no cumplirse las exigencias impuestas a su titular para hacerla efectiva). Puede afirmarse que pesa sobre el titular de este derecho una 'carga' que consiste en hacerlo valer en la oportunidad que 
en nuestro concepto, procede en la medida que la compensación económica sea meramente asistencial (artículo 55 inciso $2^{\circ}$ LMC. $)^{50}$. En todo caso, el que se deban presentar estos pactos a la aprobación judicial, no quiere decir que no se puedan celebrar antes del divorcio o la nulidad. De esta manera, estos pactos se rigen por el principio de la intangibilidad del contrato, pero para poder generar sus efectos -y la renuncia sólo los produce en el contexto de la regulación de la nulidad o del divorcio- requieren de aprobación judicial. No es una aprobación en el sentido de los actos patrimoniales, sino es un control de contenido que se debe dar en el juicio de nulidad o divorcio o en la sentencia definitiva que pone término al matrimonio. No parece razonable exigir la aprobación judicial del pacto al tiempo en que se suscribe, como si se trata de un pacto prematrimonial, porque no se sabe si el cónyuge renunciante estará en una situación de desamparo, que sea incompatible con la renuncia. Este análisis se ve confirmado por lo establecido en el artículo 1717 CC., es decir, no se admite la renuncia a un derecho consustancial al matrimonio, de los que tienen la calidad de derechos indisponibles ${ }^{51}$, y, si bien, las normas referidas a la compensación económica no hacen ninguna alusión expresa a una prohibición en este sentido, o sea, no determinan en qué caso un derecho

corresponde. El artículo 64 de la LMC es claro en cuanto este derecho debe alegarse en la demanda de nulidad o divorcio, o en la respectiva reconvención o inmediatamente después de la audiencia de conciliación, luego de la advertencia que el juez está obligado a hacer en cuanto a la existencia de este derecho, y antes que los autos pasen a la etapa siguiente. Creemos que es conveniente, en este último evento, que el juez fije un plazo breve para el ejercicio del derecho antes de dar curso progresivo a los autos en conformidad con el artículo 55 y siguientes de la Ley 19.968 sobre Tribunales de Familia. De esta manera, desaparece la incertidumbre que se genera por el hecho de no haberse ejercido el derecho en la demanda de divorcio ni en la reconvención'. 7. Que estos sentenciadores comparten el criterio antes expuesto, toda vez que si se estimare que caduca el derecho a la compensación económica al no ejercerse en la demanda, o en escrito complementario o al reconvenir, junto con contestar la demanda, la obligación que el inciso $2^{\circ}$ del artículo 64 de la Ley de Matrimonio Civil impone al juez carecería de sentido. 8. Que, en suma, se permite la reconvención en audiencia, excepcionalmente, respecto de la compensación económica porque resulta ilógico que el artículo 64 ya mencionado no tenga aplicación, considerando además que no fue derogado por la ley 20.286. 9. Que la omisión en que se ha incurrido de privar a la demandada de ejercer su derecho a compensación económica en la audiencia preparatoria de 13 de enero pasado, tanto porque no se le aceptó la reconvención presentada por estimarse extemporánea cuanto porque no se le otorgó la posibilidad de reconvenir en audiencia, configuran vicios que hacen procedente la casación formal del fallo de primer grado, ya que se ha omitido un trámite esencial en materia de divorcio".

${ }^{50}$ En este sentido, lo hemos planteado en BARCiA, R. - Riveros, C., El carácter extrapatrimonial de la compensación económica, en Revista Chilena de Derecho (en proceso de publicación).

${ }^{51}$ Domínguez, Carmen, Compensación económica en la nueva ley de matrimonio civil (Santiago, Colegio de Abogados de Chile, 2005), p. 14. 
es disponible o no, creemos que los supuestos asistenciales, contemplados en el artículo 62 inciso $1^{\circ}$ LMC., son derechos de esta naturaleza.

\section{Conclusión}

A modo de conclusión creemos que, en general, el Derecho de familia se sustenta en la autonomía privada, pero sólo en situaciones de equilibrio o normalidad y el principio de la protección del cónyuge débil se activa bajo ciertas circunstancias en las cuales dicha normalidad se transgrede. Las normas relativas a la compensación económica no establecen reglas claras acerca de la renuncia, entregando a la doctrina y los tribunales la tarea de determinar si se permite dicha renuncia y, en el evento de ser permitida, si se establecen o no límites a ella.

Esta forma de entender la compensación económica se relaciona además, con una aplicación estatutaria del Derecho de familia, por la cual los derechos que se otorgan deben interpretarse e integrarse conforme a una serie de principios, máximas y normas a las que hemos recurrido en nuestro trabajo. De este modo, la compensación económica es renunciable; pero el juez debe efectuar un control de contenido de legalidad de la renuncia, desechándola en la medida que uno de los cónyuges sea considerado como cónyuge débil. En estos supuestos, la función de la compensación económica es exclusivamente asistencial o parcialmente asistencial, independientemente que se deben cumplir los requisitos de procedencia de la compensación que establece en el artículo 61 LMC. Así, el rechazo a la renuncia se sustenta en que se pruebe que el cónyuge renunciante, a la fecha del divorcio o nulidad, está en alguno de los supuestos asistenciales, establecidos en el artículo 62 inciso $1^{\circ}$ LMC., y la compensación económica sería renunciable respecto de los criterios netamente resarcitorios de determinación de su monto.

\section{BIBLIOGRAFÍA}

Aldunate, Eduardo - Fuentes, Jessica, El concepto de derecho de propiedad en la jurisprudencia constitucional chilena y la teoría de las garantias de instituto, en Revista de Derecho de la Universidad Católica de Valparaíso, 18 (1997): Actas de las XXVII Jornadas de Derecho Público.

Barral, Inmaculada, La separación de bienes, en Maluduer de Motes, Carlos (coordinador), Derecho de familia. Análisis desde el Derecho catalán (Barcelona, Bosch, 2000).

BARRIENTOS, Javier, La compensación económica como 'derecho' de uno de los cónyuges y 'obligación' correlativa del otro. De sus caracteres, en Revista Chilena de Derecho Privado, 11 (2007).

Borth, Helmut, en Schwab, Dieter (editor), Handbuch des Scheidungsrechts (4a edición, München, Vahlen, 2000). 
Bossert, Gustavo - Zannoni, Eduardo, Manual de Derecho de familia (5 a edición, Buenos Aires, Astrea, 2004).

Corral, Hernán, El crédito de participación en los gananciales en el sistema económico matrimonial chileno, en CORRAL, Hernán (editor), Los regimenes matrimoniales en Chile (Santiago, Universidad de los Andes, 1998).

CORRAL, Hernán, La compensación económica en el divorcio y la nulidad matrimonial, en Revista Chilena de Derecho, 34 (2007) 1.

Di Fabio, Udo, Der Schutz von Ehe und Familie: Verfassungsentscheidung für die vitale Gesellschaft en Neue Juristische Wochenachrift (2003).

Domínguez, Carmen, Compensación económica en la nueva Ley de matrimonio civil, (Santiago, Colegio de Abogados de Chile, 2005).

EgeA, Jean Pensión compensatoria y pactos en previsión de una ruptura matrimonial, en Estudios juridicos en homenaje al profesor Luis Diez-Picazo (Madrid, ThomsonCivitas, 2002), III.

GARCía, María Paz, La pensión compensatoria tras la separación o el divorcio en el derecho español, en Cuadernos de Análisis Jurídicos, Colección Derecho Privado, V: Compensación Económica por Divorcio o Nulidad (Santiago, Ediciones de la Universidad Diego Portales, Escuela de Derecho, 2009).

GARCía, María Paz, Los pactos prematrimoniales de renuncia a la pensión compensatoria en el Código Civil, en Anuario de Derecho Civil, 56 (2003) 4.

Gernhuber, Joachim - Coester-Waltjen, Dagmar, Lebrbuch des Familienrechts ( $5^{a}$ edición, München, C. H Beck, 2006).

Gómez De La Torre, Maricruz, Compensación económica en la nueva Ley de matrimonio civil (Santiago, Colegio de Abogados de Santiago de Chile, 2005).

Johannsen, Kurt - Henrich, Dieter - Büttner, Helmut, Eherecht (4a edición, München, C. H Beck, 2003).

LANGenfeld, Gerrit, Handbuch der Eheverträge und Scheidungsvereinbarungen (4a edición, München, C.H Beck, 2000).

Larenz, Karl - Wolf, Manfred, Allgemeiner Teil des Bürgerlichen Rechts ( $9^{a}$ edición, 2004).

LEPIN, Cristián, La compensación económica. Efecto patrimonial de la terminación del matrimonio (Santiago, Editorial Jurídica de Chile, Chile, 2010).

MARIN, Teresa, Acuerdos de los cónyuges en la pensión por separación y divorcio (Valencia, Tirant lo Blanch, 1995).

MARTINY, Dieter, Ehescheidung und nachehelicher Unterhalt in Europa, en Electronic Journal of Comparitive Law (2004) [disponible en: http://www.ejcl.org/83/art.83$\mathrm{hmtl}]$.

Meder, Stephan, Der Unterhaltsverzicht im Spannungsfeld von Privatautonomie und öffentlichem Interesse en Familie und Recht, 1 (1993).

Novales, Aránzazu, La compensación económica como derecho de familia. ¿Cuál es el objeto de la compensación? en Revista Chilena de Derecho de Familia, 1 (Santiago, Centro de Investigaciones Jurídicas, Facultad de Ciencias Jurídicas y Sociales de la Universidad Central de Chile, 2009).

Pastor, Francisco, Estudios doctrinales, en Revista de Derecho de Familia, 28 (Valladolid, 2005).

PASTOR, Francisco, La renuncia anticipada a la pensión compensatoria en capitulaciones matrimoniales en Revista de Derecho de Familia, 19 (Valladolid, 2003). 
Pieroth, Bodo - Schlink, Bernard, Grundrechte Staatsrecht II, (18 a edición, Heidelberg, C.F Müller, 2002).

Pizarro, Carlos - Vidal, Álvaro, La compensación económica por divorcio o nulidad matrimonial, (Santiago, LegalPublishing - Abeledo Perrot, 2009).

Pizarro, Carlos, La compensación económica en la Nueva Ley de matrimonio civil, en Revista Chilena de Derecho Privado, 3 (2004).

Probert, Rebecca, Cretney and Probert Family Law (7 $7^{\text {a }}$ edición, Sweet \& Maxwell, Thomson Reuters, 2009).

Rodríguez, Pablo, Regimenes matrimoniales (Santiago, Editorial Jurídica de Chile, 1996).

SAURA, Beatriz, La pensión compensatoria. Criterios delimitadores de su importe y extensión (Valencia, Tirant lo Blanch, 2004).

SCHERPE, Jens, Englisches Familienrecht: Miller und McFarlane. Das House of Lords entscheidet erneut über Güteraufteilung nach Ehescheidung, en Zeitschrift für das gesamte Familienrecht-Ehe und Familie im privaten und öffentlichen Recht, (2006), pp. 1314 y ss.

VIDAL, Álvaro, La compensación económica por ruptura matrimonial. Una visión panorámica, en Cuadernos de Análisis Juridicos, Colección Derecho Privado, V: Compensación económica por divorcio o nulidad (Santiago, Ediciones Universidad Diego Portales, Escuela de Derecho, 2009).

Weinreich, Gerd - Klein, Michael, Kompakt Kommentar Familienrecht (Luchterhand, Kriftel, 2002). 
